\title{
Avoiding ED transport of elders: a need for an integrated multidisciplinary approach
}

\author{
Sophie Gosselin ${ }^{1}\left[\right.$ ] $\cdot$ Marcel Émond ${ }^{2} \cdot$ Lyne Marquis $^{3}$
}

Received: 24 September 2021 / Accepted: 5 October 2021

(C) The Author(s), under exclusive licence to Canadian Association of Emergency Physicians (CAEP)/ Association Canadienne de Médecine d'Urgence (ACMU) 2021

Canada's population is aging and with such demographic changes come challenges and opportunities. In this issue of CJEM, Leyenaar and colleagues [1] explore how different paramedicine programs in Ontario offer care to elderly patients at home. In attempting to map the landscape of these varied programs, they noted differences in the community paramedicine patients and the usual homecare patients. These findings are worth further exploration as they highlight vulnerable populations whose needs are likely insufficiently met by the current healthcare system design.

Leyenaar's Community programs discovered a higher proportion (compared to home care or community support programs) of patients with chronic comorbidities but also anxiety disorder and depression as illustrated by their Fig. 1. Moreover, an alarming rate of social precarity is also reported: home in disrepair, inadequate heating or cooling, limited access to certain rooms in the home. More than $50 \%$ had called 911 in the last 3 months and almost as many were hospitalized. Is it not disconcerting that despite recent hospitalization, many of these patients do not seem to have been, in some fashion, connected to home care or community support systems?

Frequent callers to already strained EMS services are more often transported to hospital by ambulance. Successful community paramedicine programs have reported decrease

Sophie Gosselin

sgosselinmd@gmail.com

1 Chef du Département de Médecine d'urgence CISSS Montérégie-Centre, Full Professor, Academic Emergency Department, McGill University, 3120 boulevard Taschereau, Greenfield Park, Qc J4V 2H2, Canada

2 FRQS, Associate Professor, Emergency Physician and Trauma Team Leader, Clinicien Chercheur-Chevronné Université LavalCHU de Québec, Quebec, QC, Canada

3 Directrice Générale Adjointe Aux Programmes Sociaux, Réadaptation et Cancérologie, CISSS de La Montérégie-Centre, Quebec, Qc, Canada use of 911 and EMS transport after their implementation [2]. This redirection of 911 calls to alternative care settings instead of the emergency department (ED) proves that a call to 911 for an apparent medical issue does not always mean that an ambulance transport to hospital is required. In some jurisdictions, there is a legal requirement that a call to EMS results in an ambulance to hospital unless the patient voluntarily refuses the transport. Perhaps it is time to review this legal framework to encompass other alternatives that would reduce the load on the ED?

An ED as the only source of urgent care can be deleterious for this aging population. Publications highlight the inherent adverse effects to having elders brought to ED. Unfamiliar environments exacerbate cognitive deficits and anxiety, leading to behavioral outbursts and use of sedative pharmacotherapy. An ED stay can induce delirium in one patient out of 10. Delirium increases the overall hospital length of stay by 4 days with the inevitable consequence of backflow overcrowding in the ED [3]. Prolonged ED length of stay and hallway boarding are also independent factors for acute delirium in elders [4]. Time to collect collateral information necessary to organize a safe discharge can lead to deconditioning [5]. The latter is a significant medical condition, difficult to reverse, and leading to potential further ED visits.

In addition to avoiding the negative impact the ED and hospital visits can have for elders, the benefit of having community paramedics going to patients' home is also one of a medico-social safety net. The community paramedic's eyes can report on what is often unsaid and underappreciated: too many elders are lonely, without adequate social support. Many are also without the required skills or means to procure what they need and effectively connect, in the 
ever-growing modern digital world, to community healthcare resources. Networking among prehospital care services is a cornerstone of optimizing elder care to avoid what is often perceived as an unnecessary transport of an already frail patient to an acute, somewhat unfriendly, environment.

Emergency physicians with interest or expertise in prehospital medicine could play a collaborative role with all community and primary care services to develop alternative pathways to emergency visits for our elders and other vulnerable populations. While these programs are being piloted or implemented, perhaps a medical backup service could also be considered to assist community paramedics in decision making for ambiguous clinical situations?

Emergency departments should not be the place to find out our elders have nothing to eat, need help taking their medication, or live in precarious conditions. Ultimately, community paramedicine brings eyes into the world of our elders. This helps us figure out how to give them the care they need, in their home or another non hospital setting, without subjecting them to unnecessary transport to the ED. Community paramedics can also appreciate when returning or staying at home is dangerous, and the hospital is unfortunately, the safest place to be until another solution can be found.

\section{Declarations}

Conflict of interest The authors declare no conflict of interest.

\section{References}

1. Leyenaar MS, McLeod B, Jones A, Brousseau AA, Mercier E, Strum RP, et al. Paramedics assessing patients with complex comorbidities in community settings: results from the CARPE study. CJEM. 2021. https://doi.org/10.1007/s43678-021-00153-4.

2. Agarwal G, Angeles R, Pirrie M, McLeod B, Marzanek F, Parascandalo J, et al. Reducing 9-1-1 emergency medical service calls by implementing a community paramedicine program for vulnerable older adults in public housing in Canada: a multisite cluster randomized controlled trial. Prehosp Emerg Care. 2019;23(5):718-29. https://doi.org/10.1080/10903127.2019. 1566421.

3. Emond M, Boucher V, Carmichael PH, Voyer P, Pelletier M, Gouin E, et al. Incidence of delirium in the Canadian emergency department and its consequences on hospital length of stay: a prospective observational multicentre cohort study. BMJ Open. 2018;8(3): e018190. https://doi.org/10.1136/bmjop en-2017-018190.

4. van Loveren K, Singla A, Sinvani L, Calandrella C, Perera T, Brave M, et al. Increased emergency department hallway length of stay is associated with development of delirium. West J Emerg Med. 2021;22(3):726-35. https://doi.org/10.5811/westjem.2021.1. 49320.

5. Gillis A, MacDonald B. Deconditioning in the hospitalized elderly. Can Nurse. 2005;101(6):16-20. 